\section{DISEASES OF THE CHEST}

Described for use of Practitioners by Robert Coope, M.D., F.R.C.P. Published by E. \& S. Livingstone, Edinburgh. 1944. Price 253.

As one who during his student years was taught by Robert Coope the reviewer looked forward to the publication of this manual with considerable interest and excitement. In his teaching Robert Coope always put forward the essentially practical method of diagnosis and coupled this with a sense of the academic value of straightforward thinking such as is not often found in the teaching physician. Therefore, it came as no surprise to be able to read this book and to learn much that was of great interest and value in the study of respiratory disease.

It was only some years after qualification that the reviewer came to realise the significance of simple elementary thinking in terms of the bed-rock facts of anatomy and physiology, and as Lord Horder says in the preface: "this process the author follows with admirable consistency throughout the book." This one feature alone is sufficient commendation for any student or practitioner.

The book itself is well illustrated, not by beautiful radiographs, but more with small practical diagrams, many of which are quite admirable; giving succinctly all the necessary information for the reader, especially for one who has a visual mind. It is a book that may well be read by every post-graduate, whether or not he is interested in chest diseases or whether or not he feels that he knows as much as he wants to about that particular section of medicine; for it is a textbook, unique in its presentation and admirable in its literary attainments.

It is, of course, possible to pull certain sections of the book to pieces, but it is felt that to do this would serve no really useful purpose. The fact that in diagram 240 the bifurcation of the trachea into the main bronch 3 suggests that the right and left bronchi come off at equal? angles does not in any way belittle the value of the boolo or even that particular diagram. The fact that the reviewer does not feel that the subject of asthma, chronic bronchitis and emphysema has received all the attention which this group of economic diseases require, is of very? little moment to any but the reviewer or the specialist.

To many readers, the fact that the section on pulmonary tuberculosis is relatively short may be a little tiresome, but the length of any one section does not reflect the value of what is written therein. Sound technical knowledge and good common sense written in the space of a few hundred words is indeed of greater value thano thousands written about irrelevancies.

We feel that the author had this very much in mind when he set out to write his magnum opus on respiratory? diseases and there is nothing but praise to be given tor it. In substance sound, in format favourable, in reproductN tion adequate, in essentials estimable.

Any reader may be able to say to Doctor Cooper when he has read this book diligently, that his mind, at any rate in relationship to respiratory disease, has been able "to grow straight in the strength of thy spirit." This book is highly recommended and should fill a niche in our medical libraries for many years to come. 